\title{
PERBANDINGAN PENDAPATAN, CURAHAN JAM KERJA, \\ DAN TENAGA KERJA USAHA TANI TEBU RAKYAT INTENSIFIKASI \\ (TRI) DENGAN USAHA TANI PADI DI DESA KARANGMOJO \\ KECAMATAN TASIKMADU KABUPATEN KARANGANYAR TAHUN 1992/1993
}

Oleh : Dahroni

\begin{abstract}
$\overline{\text { ABSTRACT }}$
The intensification of People, sugar cane plantation program, or the TRI (in Indonesia), is a national program which, has been in function since the anactment of The Presidental Instruction Number 9 of 1975. Considering the TRI program as a national program, and as the farmers are considered as the target groups, the study is aiming at measuring a comparison between the income of farmers of the TRI farming system and that the rice growing farmers. The study also aims at measuring the time allocation utilized by each farming branch in Karangmojo Village, Tasikmadu Subdistrict, Karanganyar Regency, Central Java.

The study was carried out using the survey method, whereas samples were taken using the sampling method. The sample region, which, at the same time, was determined as the location of the study, was selected out purposively.

The respondents selected for the study are farmers engaged in the TRI program, paddy farmers, and farm labourers. Respondents, who are 55 in total, consist of Groups I, II, and III consisting of 11, 21, and 23 TRI and paddy farmers respectively.

The study used primary as well as secondary data obtained through conducting free interview to inhabitants or public figures related with the study. Primary data collected are the income of farmers of the TRI and paddy farming, whereas the secondary data are collected from the data of the inhabitants, size of landuse, irrigation, precipitations, the TRI or sugar-cane manufacturing, and the volume of the sugar-cane rendements.

The study shows that the income of the TRI farmers is smaller (Rp. 1,921,866) than that of the paddy farmers (Rp. 2,291,363.00). The working hours and time allocation of TRI farming are also smaller (1,937,95 hours and 105 men's work) than those of paddy farming which is 2,237, 29 hours and 158 men's work.

Besides, certain problems emerged, among others : complaints, coming from farmers of the glebagan target system. Which was carried with unjust consideratons, unclear
\end{abstract}


calculations concerning the contents of sugar cane rendements, and various obscured deductions which inflich a loss to the farmers welfare

Key Words : the life of sugar cane farmers .. sugar cane and paddy production .. farmers and sugar cane farming problems.

\section{$\overline{\text { INTISARI }}$}

Program Tebu Rakyat Intensifikasi (TRI) adalah program nasional yang mulai dilaksanakan sejak dikeluarkannya Inpres Nomor 9 Tahun 1975. Mengingat arti pentingnya program TRI sebagai program nasional dan kelompok sasaran yang dituju yakni para petani, maka penelitian ini bertujuan untuk mengukur besarnya perbandingan pendapatan petani dari usaha tani TRI dengan pendapatan petani dari usaha tani padi. Penelitian ini juga bertujuan untuk mengukur besarnya curahan jam kerja yang dimanfaatkan dari masing-masing cabang usaha tani di Desa Karangmojo, Kecamatan Tasikmadu, Kabupaten Karanganyar.

Dalam penelitian ini metode yang digunakan yakni metode survai dan penentuan sampel dilaksanakan secara sampling. Sampel wilayah dan sekaligus sebagai daerah penelitian, ialah ditentukan secara purposife.

Responden dalam penelitian ini ialah petani yang berusaha pada TRI, petani padi, dan buruh tani. Pengambilan responden dilakukan dengan cara mengambil 55 responden, terdiri dari Kelompok I sebanyak 11 sampel petani TRI dan padi, Kelompok II sebanyak 21 sampel petani TRI dan padi, dan Kelompok III sebanyak 23 sampel petani TRI dan padi.

Data yang diambil dalam penelitian ini yakni data primer dan sekunder ditambah data yang diperoleh melalui wawancara bebas kepada pamong penduduk yang ada hubungannya dengan penelitian ini. Jenis data primer yang dikumpulkan berupa pendapatan petani dari usaha tani TRI dan usaha tani padi. Data sekunder yang dikumpulkan antara lain data penduduk, luas penggunaan lahan, pengairan, curah hujan dan pengolahan TRI beserta besarnya rendemen tebu.

Hasil penelitian ini menunjukkan bahwa pendapatan dari usaha tani TRI lebih kecil daripada pendapatan usaha tani padi (pendapatan usaha tani padi banyak $R p$. 2.291.363,90 sedangkan usaha TRI Rp. 1.921.866,12). Curahan jam kerja (jam kerja dan tenaga kerja) yang dimanfaatkan dari usaha tani TRI lebih kecil daripada usaha tani padi (jumlah jam kerja usaha tani padi sebanyak 2.237,29 jam dan usaha TRI sebanyak 1.937,95 jam, jumlah tenaga kerja usaha tani padi 158 orang dan usaha TRI 105 orang).

Disamping, itu ada keluhan perihal persoalan-persoalan yang dihadapi oleh para petani sistem target glebagan, yang tanpa disadari pertimbangan-pertimbangan,

104 Forum Geografi No. 14 dan 15 Th. VIII/Juli dan Desember 1994 
perhitungan kadar rendemen tebu tidak jelas dan potongan-potongan yang tidak jelas pula.

\section{$\overline{\text { PENGANTAR }}$}

Semenjak diberlakukannya Instruksi Presiden (Inpres) No. 9 Tahun 1975 tentang Program Tebu Rakyat. Intensifikasi (TRI) terjadi perubahan yang mendasar tentang sistem produksi gula di Indonesia, dimana pengusahaan tebu dilakukan oleh petani sedangkan pabrik gula (PG) bertindak sebagai pengolahnya.

Adapun tujuan diberlakukannya program TRI adalah :

1. Pengalihan sistem sewa tanah/lahan menjadi sistem pengolahan petani di atas lahan sendiri.

2. Peningkatan produksi gula nasional.

3. Peningkatan pendapatan petani.

4. Peningkatan perluasan kesempatan kerja.

Disamping itu, tujuan akhir sistem TRI dimaksudkan agar petani tebu menjadi 'wiraswasta' yang mampu berusaha dan mandiri, dalam bentuk kelompok tani maupun koperasi petani dan mempunyai kedudukan ekonomi yang kuat.

Untuk mencapai tujuan yang terkandung dalam inpres tersebut maka dalam pelaksanaannya ditunjang dengan kebijaksanaan lainnya berupa pemberian kredit kepada petani peserta, sistem bagi hasil, bimbingan teknis budidaya tebu, rehabilitasi dan pembangunan pabrik gula serta perluasan areal tebu baik di lahan sawah maupun lahan tegalan yang ada di Jawa maupun di luar Jawa.

Demikian pula di daerah penelitian yang merupakan lingkungan pabrik gula Tasikmadu juga terkena program TRI. Daerah penelitian yang terletak di dataran kaki gunung api merupakan daerah yang tanahnya subur dan cocok untuk pertanian baik tanaman padi maupun tanaman tebu. Hingga tahun 1992/1993 daerah penelitian sudah melaksanakan program TRI selama 18 tahun (dimulai sejak musim tanam tahun 1976/1977).

\section{PERUMUSAN MASALAH}

Di dalam pengusahaan program TRI maka petani di Desa Karangmojo Kecamatan Tasikmadu Kabupaten Karanganyar yang merupakan lokasi daerah penelitian memerlukan waktu paling cepat 10-12 bulan. Dalam jangka waktu yang sama petani di Desa Karangmojo dapat mengusahakan 3 (tiga) kali panen padi.

Dalam penelitian ini maka dicari apakah ada perbedaan yang nyata sehingga petani dapat memilih usaha taninya yang mendatangkan keuntungan/pendapatan yang lebih besar dengan diberlakukan program TRI.

Secara sederhana maka permasalahan di daerah penelitian tersebut dapat dirumuskan sebagai berikut : Apakah ada perbedaan antara usaha tani TRI dengan usaha tani padi dalam 
hal pendapatan, pemanfaatan jam kerja, dan jumlah tenaga kerja yang terlibat?

\section{TUJUAN PENELITIAN}

Tujuan penelitian ini adalah sebagai berikut :

1. Untuk mengetahui besarnya perbedaan pendapatan petani, antara program TRI dengan usaha tani padi.

2. Untuk mengetahui besarnya perbedaan pemanfaatan jumlah jam kerja antara usaha tani TRI dengan usaha tani padi.

3. Untuk mengetahui besarnya perbedaan jumlah tenaga kerja yang dilibatkan pada usaha tani TRI dengan Usaha tani padi.

\section{CARA PENELITLAN}

Daerah Penelitian

\section{Letak dan Batas}

Secara astronomis Desa Karang mojo yang merupakan daerah penelitian terletak antara : $7^{\circ} 34^{\prime} 32^{\prime \prime}$ LS sampai dengan $7^{\circ} 38^{\prime} 43^{\prime \prime}$ LS dan $110^{\circ}$ $50^{\prime} 45^{\prime \prime}$ sampai dengan $110^{\circ} 54^{\prime} 64^{\prime \prime}$ BT (Peta Topografi sheet 519 i sekala 1: $50.000)$

Secara administratif Desa Karang mojo termasuk Kecamatan Tasik madu, Kabupaten Daerah Tingkat II Karanganyar, Propinsi Daerah Tingkat I Jawa Tengah. Daerah penelitian, jarak pemerintah (orbitasi) dari Kota Kabupaten Dati II 7 km ke arah barat. Wilayah Desa Karangmojo meliputi 7 pedusunan yaitu :

1. Dusun Karangmojo

2. Dusun Dermen

3. Dusun Karangwuni

4. Dusun Karangdowo

5. Dusun Wates

6. Dusun Ngablak

7. Dusun Tangkilan.

Berdasarkan wilayah administrasinya Desa Karangmojo dibatasi oleh desa-desa sebagai berikut :

(a) Sebelah utara : berbatasan dengan Desa Kaling, Kecamatan Tasik madu.

(b) Sebelah selatan : berbatasan dengan Desa Buran, Kecamatan Tasikmadu.

(c) Sebelah barat : berbatasan dengan Desa Jetis, Kecamatan Tasikmadu.

(d) Sebelah timur : berbatasan dengan Desa Pandeyan, Kecamatan Tasikmadu.

2. Luas dan Penggunaan Lahan

Desa Karangmojo Kecamatan Tasikmadu seluas $269,6545 \mathrm{Ha}(2,96$ $\mathrm{km}^{2}$ ). Lahan seluas ini terdiri dari tanah pertanian (sawah), tegal, kolam, dan permukiman. Adapun perincian dari luas lahan di daerah penelitian dapat dilihat pada tabel 2.1.

Luas lahan berpengaruh terhadap modernisasi di bidang pertanian, khususnya program TRI karena bagi petani yang lahannya sempit pada umumnya lahan tersebut merupakan gantungan hidup yang utama. Mereka tidak mau spekulasi, karena menanam tebu yang mempunyai umur lebih 
Tabel 2.1. Luas Desa Karangmojo, Didasarkan Penggunaan Lahannya Tahun 1992/1993

\begin{tabular}{|r|l|c|c|}
\hline No. & \multicolumn{1}{|c|}{ Penggunaan Lahan } & Luas Lahan(Ha) & Persentase (\%) \\
\hline 1. & Tanah Sawah : & 224,4255 & 75,7 \\
& $\begin{array}{l}\text { a. Irigasi teknis } \\
\text { b. Irigasi setengah Teknis }\end{array}$ & - & - \\
& $\begin{array}{l}\text { c. Tadah hujan } \\
\text { 2. }\end{array}$ & - & - \\
Perumahan dan Pekarangan & Tambak / Kolam & 65,9755 & 22,2 \\
4. & Lain - lain & 6,2535 & - \\
\hline & J u m l a h & 296,6545 & 2,1 \\
\hline
\end{tabular}

panjang dari selain tanaman tebu (tanaman pokok padi) dan mempunyai resiko lebih besar.

Indikator yang mempengaruhi keputusan petani yang paling baik adalah luas lahan, status pemilikan tanah, intensitas tanaman, dan tingkat komersialisasi usaha tani (Lukito, 1981). Pengetrapan teknologi baru di sektor

penting karena merupakan tempat usaha tani dilakukan.

Dengan melihat distribusi pendapatan maka perlu diketahui penguasaan lahan oleh penduduk yaitu lahan yang dimiliki. Berikut ini tabel memperlihatkan penguasaan lahan di daerah penelitian dari 55 responden untuk mengikuti program TRI.

Tabel 2.2. Pemilikan Lahan Desa Karangmojo Tahun 1992/1993

\begin{tabular}{|c|c|c|c|}
\hline No. & \multicolumn{1}{|c|}{ Luas Lahan (Ha) } & Jumlah (orang) & Persentase (\%) \\
\hline 1. & $<0,25$ & 5 & 9 \\
2. & $0,25-0,50$ & 48 & 87 \\
3. & $0,50-0,75$ & 2 & 4 \\
4. & $0,75<$ & 0 & 0 \\
\hline & J u m l a h & 55 & 100 \\
\hline
\end{tabular}

Sumber : Data hasil olahan data primer

pertanian akan mendapat respon dari petani jika petani tersebut mempunyai tanah garapan yang luas (Birowo, AT. 1973). Tanah memiliki dua fungsi yaitu fungsi sosial dan fungsi ekonomi. Secara ekonomis semakin luas lahan yang dikuasai semakin banyak produk yang dapat dihasilkan. Lahan merupakan faktor produksi yang sangat
Berdasarkan tabel tersebut di atas, dapat dikemukakan bahwa sesuai hasil wawancara dari keterangan yang disampaikan 48 responden (87\%) dari 55 responden data tersebut sebagian besar di daerah penelitian mempunyai tanah garapan yang relatif sempit (rata-rata 0,355 ha). Apabila tanah 
garapan relatif sempit maka pendapatan juga relatif masih kecil/ rendah.

Pada umumnya dalam masyarakat pertanian struktur masyarakatnya dapat dilihat berdasarkan pada pemilik an lahan (Soekanto, 1986). Luas lahan yang dimiliki merupakan indikator status seseorang, dimana semakin luas lahan yang mereka miliki maka semakin tinggi pula statusnya.*

Data di atas memperlihatkan bahwa pemilikan lahan petani yang sempit akan berpengaruh pula terhadap tingkat kehidupan petani. Apalagi lahan yang sempit ini kena peraturan program TRI, padahal tanah sebagai sumber pendapatan mereka dengan keterbatasan yang mereka miliki membuat mereka sulit untuk mencari sumber pendapatan hingga menjelang panen tiba. Bantuan dari kredit Bank Rakyat Indonesia (BRI), kepada petani TRI sebelum panen dengan melalui perantaraan koperasi unit desa (KUD). Kredit tersebut untuk menunjang pengelolaan tanaman tebu merupakan pinjaman kredit dari pemerintah. Namun tidak jarang petani mempergunakan kesempatan tersebut untuk memenuhi di luar kebutuhankebutuhan petani guna pengelolaan TRI.

Dengan demikian ketergantungan petani terhadap kredit dalam pelaksanaan TRI merupakan masalah yang memang harus dilaksanakan, karena pada awal penanaman petani banyak mengeluarkan biaya, serta hasil dari usaha TRI akan diperoleh setelah tebang, masa tanam hingga tebang untuk tanaman tebu memerlukan jangka waktu yang relatif lama.

\section{RESPONDEN PENELITIAN}

Dalam penelitian ini digunakan metode survei, yaitu pengamatan atau penelitian yang kritis untuk mendapatkan keterangan yang baik dan terang terhadap suatu persoalan tertentu dan di dalam suatu daerah tertentu (Winarno Surachmad, 1970 : 80).

Sebagai sampel adalah rumah tangga petani yang pada periode yang sama menanam tebu (TRI) dan menanam padi. Pemilihan sampel petani TRI diambil secara acak dari 184 petani TRI dan padi diambil sebanyak 55 responden. Dari 184 petani TRI dan padi terbagi menjadi 3 kelompok kerja oleh karena itu pemilihan sampel dapat dibagi sebagai berikut :

1. Kelompok I, petani TRI dan petani padi yakni sebanyak 11 responden diambil secara acak.

2. Kelompok II petani TRI dan petani padi yakni sebanyak 21 responden diambil secara acak.

3. Kelompok III petani TRI dan petani padi yakni sebanyak 23 responden diambil secara acak.

Pengambilan sampel sebanyak 55 responden tersebut mewakili dari populasi petani TRI dan petani padi, perolehan hitungan adalah sisa lahan yang terkena sistem glebagan TRI yang pada saat ditanami padi 
diperhitung kan sama luasnya dengan yang ditanami TRI dalam satu kesatuan waktu yang sama. Adapun rincian luas lahan yang ditanam TRI rata-rata $0,355 \mathrm{Ha}$, sedangkan untuk tanaman padi diperhitungkan sesuai dengan luas rata-rata tanaman TRI. Bila dihubungkan dengan sistem glebagan pertahunnya dapat dilihat pada gambar sebagai berikut :
5. Jam kerja yang dimanfaatkan dalam usaha tani tersebut.

6. Jumlah tenaga kerja yang dilibatkan dalam kedua dari usaha tani tersebut.

Untuk memperoleh data pen dapatan usaha tani yang bersih diperoleh dari pendapatan kotor, dikurangi dengan biaya produksi beserta bunga pinjaman. Dalam membandingkan

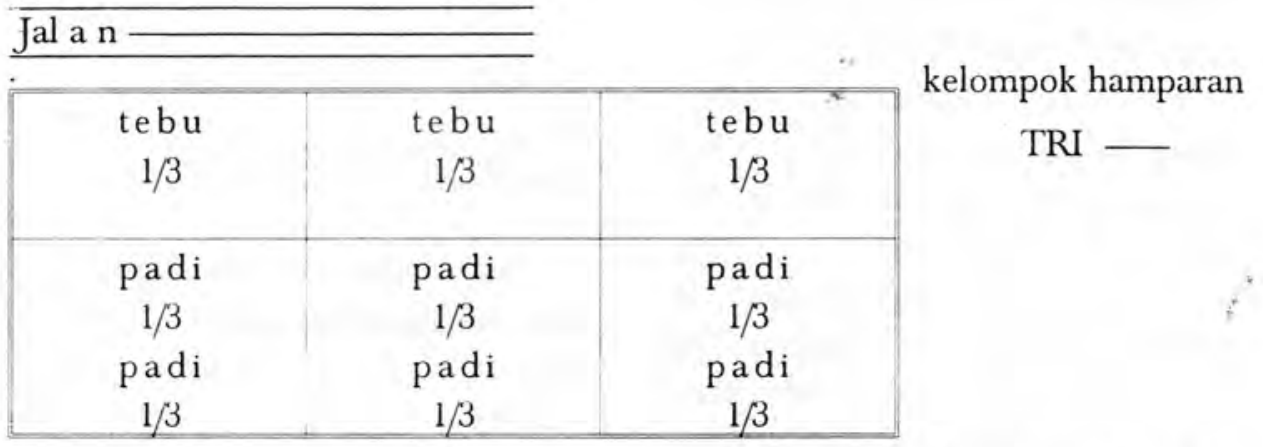

\section{PENGAMBILAN DATA}

Pengumpulan data primer, yaitu data cara perolehannya langsung dari penduduk dengan menggunakan teknik wawancara dan dengan tinjauan daerah untuk melengkapi data sekunder, data tersebut adalah :

1. Pendapatan petani dari usaha tani program TRI.

2. Pendapatan petani dari usaha tani padi.

3. Biaya anggaran dari usaha tani program TRI, dan biaya anggaran dari usaha tani padi antara lain: sarana produksi dan tenaga kerja.

4. Bung pinjaman pendapatan dan kesempatan kerja dari kedua usaha tani tersebut diperhitungkan dalam luas lahan yang sama dan waktu yang sama. Disamping itu juga memanfaatkan data sekunder, data dari kantor pemerintahan setempat diperoleh dari catatan-catatan atau dokumen yang terdapat di kantor atau instansi yang terkait ada hubungannya dengan penelitian, macamnya data tersebut antara lain : (a) data demografi (b) luas penggunaan lahan (c) pola penggunaan lahan (d) peta ikhtisar daerah penelitian, letak dan batas daerah penelitian ( $\mathrm{f}$ ) data penggunaan pengairan $(\mathrm{g})$ data curah hujan (h) dan data hasil pengolahan TRI (dari PG Tasikmadu). 


\section{$\overline{\text { ANALISA DATA }}$}

Di dalam menganalisis dana untuk mengetahui perbedaan pendapatan dari kesempatan kerja dari kedua cabang usaha tani tersebut digunakan analisa tabel.

Untuk mengukur perbedaan pendapatan dan penyerapan tenaga kerja dari kedua cabang usaha tani tersebut signifikan atau tidak, maka digunakan statistik test untuk menganalisisnya. Formulanya dapat dilihat berikut ini :

Dari formula tersebut untuk menghitung antara dua rata-rata dihitung dari dua sampel yang ditarik dari dua po- pulasi independen dan secara ran- dom, maksudnya X1 dan X2 adalah harga rata-rata dihitung dari kedua populasi tersebut. Sedangkan S1 dan S2 adalah standart deviasi, sedangkan $\mathrm{n} 1$ dan $\mathrm{n} 2$ adalah besarnya sampel.

\section{VARIABEL}

Variabel yang digunakan untuk menguji beberapa hipotesa tersebut adalah : Variabel pengaruh atau variabel independent (bebas) yang meliputi usaha tani TRI/padi, curahan jam kerja, dan penyerapan tenaga kerja.

Variabel terpengaruh atau variabel dependent yang meliputi pendapatan dan luas lahan garapan.

\section{HASIL PENELITIAN \\ DAN PEMBAHASAN}

Dari analisa dan pengolahan datadata lapangan dan data-data sekunder diperoleh hasil penelitian sebagai berikut :

1. Pendapatan bersih petani dari usaha tani TRI di daerah penelitian

$$
\begin{aligned}
& t=\sqrt{\frac{\left|x_{1}-x_{2}\right|}{\frac{s_{1}^{2}}{n_{1}}-\frac{x_{2}^{2}}{n_{2}}}} \mid s_{2}=\sqrt{\frac{\sum\left(x_{2}-x_{1}\right)^{2}}{n-1}} \\
& s_{1}=\sqrt{\frac{\sum\left(x_{1}-x_{2}\right)^{2}}{n-1}} \mid d f=\left(n_{1}-1\right)+\left(n_{2}-1\right)
\end{aligned}
$$

$\mathrm{X}_{1}=$ Usaha tani padi

$\mathrm{X}_{2}=$ Usaha tani tebu rakyat intensifikasi

Sumber : Amudi Pasaribu (1975; 302) 
terhadap 55 responden dengan luas lahan garapan 19,5355 Ha sebesar Rp. 37.909.435,00 sedangkan pendapatan bersih petani dari usaha tani padi dengan jumlah responden 55 dan luas lahan 19,5355 Ha adalah sebesar Rp. 44.738,00

Dengan demikian petani di daerah penelitian yang mengusahakan tanaman tebu (TRI) unit II dengan luas lahan rata-rata $0,355 \mathrm{Ha}$, apabila dijadikan $1 \mathrm{Ha}(10.000 \mathrm{~m} 2)$, maka setiap 1 Hanya mana salah satu tujuan program TRI belum berhasil.

Dengan demikian perbandingan pendapatan petani dari usaha tani padi lebih besar dari pada pendapatan petani dari hasil usaha tani program TRI.

Agar lebih jelas perbandingan pendapatan petani dari lahan yang diusahakan dengan TRI dan padi per hektar per tahun (12 bulan), dapat dilihat pada tabel berikut ini.

Tabel 1 : Perbandingan Pendapatan Bersih Per Ha/Tahun

Untuk Usaha Tani Padi dan Usaha Tani TRI

Di Desa Karangmojo, Tahun 1992/1993

\begin{tabular}{|c|c|c|c|}
\hline \multirow{2}{*}{ No } & \multirow{2}{*}{ Luas Lahan(Ha) } & \multicolumn{2}{|c|}{ Pendapatan Bersih(Rp) } \\
\cline { 3 - 4 } & & Usaha Tanipadi & Usaha Tani TRI \\
\hline 1. & $0,25-0,29$ & $706.835,00$ & 627.572 .00 \\
2. & $0,30-0,35$ & $795.857,00$ & 653.378 .00 \\
3. & $0,36-0,40$ & $842.576,00$ & 743.105 .00 \\
4. & $0,41-0,45$ & $893.598,00$ & 841.313 .00 \\
\hline & Rata-rata/Ha & $2.291 .363,90$ & $1.921 .866,12$ \\
\hline
\end{tabular}

Sumber : Data hasil olahan data primer

$=1 / 0,355$ X Rp.682.262,4727 = Rp. $1.921 .866,12$ atau setiap $1 \mathrm{Ha}=\mathrm{Rp}$. $1.921 .866,12$.

Sebaliknya apabila petani menanam budidaya tanaman padi dengan luas lahan yang sama yaitu 1 Hanya diperoleh 1/0,355 X Rp. 813.434,1818 $=$ Rp.2.291.363,90 jadi setiap $1 \mathrm{Ha}$ atau perhektarnya menghasilkan Rp. 2.291.363,90. Maka selisihnya dengan tanaman tebu terdapat sebesar Rp. 369.497,78. Kenyataan ini diperoleh di daerah enelitian memperlihatkan di-
Dari tabel tersebut di atas, menggambarkan perbandingan pendapatan total bersih pengelompokan pengusahaan lahan pertanian, dari sini semakin terlihat jelas bahwa usaha tani TRI di daerah penelitian masih lebih kecil dari usaha tani padi, berarti pula usaha tani TRI yang diprogramkan oleh pemerintah belum berhasil.

Pendapatan bersih dari usaha tani yang dimaksud dalam penelitian ini adalah hasil bersih dari suatu usaha tani dihitung berdasarkan harga pro- 
duksi kotor baik dari tanaman padi maupun tanaman TRI, kemudian dikurangi dengan pengeluaran biaya produksi. Pengeluaran biaya produksi termasuk di dalamnya antara lain biaya untuk bibit, biaya untuk pupuk, biaya untuk upah tenaga kerja dan kegiatan produksi lainnya. Pendapatan bersih usaha tani padi diperoleh dengan menjumlahkan pendapatan beberapa periode masa tańam yang sama waktunya dengan satu kali masa tanam TRI.

2. Jumlah jam kerja yang dimanfaatkan petani dari usaha tani TRI dan usaha tani padi dari 55 responden dengan luas lahan garapan rata-rata usaha tani padi perhektarnya pertahun $2.273,29$ sedangkan usaha tani TRI lesaikan pekerjaan dengan harapan setelah menyelesaikan pekerjaan dengan harapan setelah menyelesaikan pekerjaannya, mereka dapat mencari pekerjaan lain untuk menambah hasil.

b. Luas areal peserta TRI disatukan dalam wadah kelompok tani hamparan, sehingga dalam menyelesaikan pekerjaan lebih efisien daripada luas areal TRI yang letaknya terpisah-pisah.

Untuk lebih jelas dalam melihat perbedaan curahan jam kerja usaha tani padi dengan usaha tani TRI, dapat dilihat pada tabel 2 yang berdasarkan pengelompokan pengusahaan luas lahan.

Tabel 2 : Perbandingan Jumlah Pencurahan Jam Kerja, Per Ha/Tahun Untuk Tani Padi dan Usaha Tani TRI, Di Desa Karangmojo, Tahun 1992/1993

\begin{tabular}{|c|c|c|c|}
\hline \multirow{2}{*}{ No } & \multirow{2}{*}{ Luas Lahan $(\mathrm{Ha})$} & \multicolumn{2}{|c|}{ Curahan Jam Kerja } \\
\cline { 3 - 4 } & & Usaha Tani Padi & Usaha Tani TRI \\
\hline 1. & $0,25-0,29$ & 604 & 514 \\
2. & $0,30-0,35$ & 819 & 685 \\
3. & $0,36-0,40$ & 844 & 774 \\
4. & $0,41-0,45$ & 946 & 840 \\
\hline & Rata-rata/Ha & $2.273,29$ & $1.937,95$ \\
\hline
\end{tabular}

Sumber : Data hasil olahan data primer

1.937,95. Untuk jam kerja yang dimanfaatkan oleh usaha tani TRI lebih kecil disebabkan karena :

a. Pada usaha tani tebu TRI tenaga kerja dibayar dengan sistem borongan, dengan demikian tenaga kerja sistem borongan ini dalam memanfaatkan waktu lebih pendek/cepat untuk menye-
Berdasarkan tabel tersebut di atas, terlihat bahwa pencurahan jam kerja berdasarkan pengelompokan pengusahaan lahan, pada usaha tani padi dan usaha tani TRI memperlihatkan perbedaan yang cukup mencolok.

3. Jumlah tenaga kerja yang terserap untuk usaha tani TRI dan usaha tani 
padi dari 55 responden dengan luas tanah garapan rata-rata usaha tani padi per hektarnya pertahun 158 tenaga kerja sedangkan usaha tani TRI 105 tenaga kerja.

Perbedaan jumlah tenaga kerja yang dilibatkan dalam kedua jenis usaha tani ini akan nampak nyata apabila dilihat berdasarkan pengelompokan luas lahan yang diusahakan. Tabel 3 menunjukkan perbedaan jumlah tenaga kerja yang dilibatkan tersebut. bandingkan usaha tani TRI. Hal-hal yang menyebabkan ketidakberhasilan usaha tani TRI sangatlah komplek namun secara garis besar disebabkan antara lain :

1. Petani tebu kurang mampu dalam penguasaan teknik budidaya tanam tebu, semuanya hanya diserahkan kepada kelompok tani.

2. Petani tebu sendiri tidak mempunyai gairah untuk menanam tebu karena beberapa masalah intern

Tabel 3: Perbandingan Jumlah Tenaga Kerja yang dilibatkan

Per Ha/Tahun Untuk Usaha Tani Padi dan Usaha Tani TRI DI desa

Karangmojo, Tahun 1992/1993

\begin{tabular}{|c|c|c|c|}
\hline \multirow{2}{*}{ No } & \multirow{2}{*}{ Luas Lahan $(\mathrm{Ha})$} & \multicolumn{2}{|c|}{ Jumlah Tenaga Kerja } \\
\cline { 3 - 4 } & & Usaha Tani Padi & Usaha Tani TRI \\
\hline 1. & $0,25-0,29$ & 54 & 44 \\
2. & $0,30-0,35$ & 55 & 46 \\
3. & $0,36-0,40$ & 58 & 47 \\
4. & $0,41-0,45$ & 63 & 52 \\
\hline & Rata-rata/Ha & 158 & 105 \\
\hline
\end{tabular}

Sumber : Data hasil olahan data primer

Memperhatikan tabel di atas (tabel 3), tampak bahwa penyerapan tenaga kerja di daerah penelitian, berdasarkan perbandingan pengelompokan luas lahan usaha tani padi dengan usaha tani TRI terdapat perbedaan yang cukup tajam. Adanya perbedaan ini disebabkan karena usaha tani tebu memerlukan cara pengelolaan yang relatif berbeda apabila dibandingkan dengan cara pengelolaan usaha tani padi.

Dari hasil penelitian dapat dikata kan petani lebih untung apabila mengerjakan usaha tani padi di- dan birokratis.

3. Petani tebu memerlukan banyak keterampilan dan keuletan teknis bercocok tanam.

4. Banyak menanggung resiko.

\section{$\overline{\text { KESIMPULAN DAN SARAN }}$}

Desa Karangmojo merupakan daerah penelitian secara administratif termasuk wilayah Kecamatan Tasik madu, daerah Tingkat II Kabupaten Karanganyar. Desa Karangmojo terletak di Kaki Gunung Lawu (Vulcanic Foot Plain) bagian barat dan me- 
rupakan daerah yang subur dengan fasilitas pengairan teratur dan baik, dengan kesuburan tersebut disamping tanahnya cocok untuk ditanami padi juga sangat cocok untuk ditanami tebu.

Di daerah penelitian tergolong lahan sawah basah dan apabila ditinjau secara geografi yakni : tanah, iklim dan irigasi teknis maka sangat mendukung sekali untuk berusaha di bidang pertanian diantara salah satunya tanaman tebu. Namun "dari hasil penelitian yang dilaksanakan beberapa waktu lalu terbukti bahwa usaha tani tebu rakyat intensifikasi (TRI) dan usaha tani padi terdapat perbedaan pendapatan dan kesempatan kerja.

Berdasarkan hasil penelitian dari segi pendapatan ternyata pendapatan dari usaha tani TRI adalah lebih kecil daripada pendapatan usaha tani padi, dan kesempatan kerja (jam kerja dan tenaga kerja) dari usaha tani TRI lebih kecil pula daripada usaha tani padi.

Yang menyebabkan ketidakberhasilan dari usaha tani TRI antara lain :

(1) Petani tebu kurang mampu dalam penguasaan teknik budi daya tanam tebu, semuanya diserahkan kepada kelompok tani.

(2) Petani tebu sendiri tidak mempunyai gairah untuk menanam tebu.

(3) Petani tebu memerlukan banyak keterampilan dan keuletan teknis bercocok tanam.

(4) Banyak menanggung resiko.

Dari hasil penelitian ternyata besarnya pendapatan dari 55 responden dengan luas tanah garapan 19.5355 $\mathrm{Ha}$, dari usaha tani TRI terdapat Rp. $37.909 .436,00$. Untuk usaha tani padi terdapat Rp. 44.738.880,00

Pemanfaatan jam kerja untuk usaha tani TRI terdapat 37.859 Jam. Untuk usaha tani padi terdapat 44.410 jam, kemudian tenaga kerja yang dibutuh kan dalam usaha tani TRI terdapat 2.407 orang, dan usaha tani padi membutuhan tenaga kerja 3.078 orang.

Apabila dilihat dari hasil penelitian di atas yakni dari segi pendapatan usaha tani TRI merugikan daripada usaha tani padi. Sedangkan kesempatan kerja banyak dimanfaatkan pada usaha tani padi.

Berdasarkan dari hasil penelitian yang telah diuraikan di atas, disini dapat dikemukakan saran-saran.

Untuk membangkitkan dan merangsang/semangat kembali terhadap gairah petani untuk berbudidaya tebu, diperlukan banyak peningkatan melalui kebijaksanaan-kebijaksanaan baru di sektor industri gula antara lain :

a. Dari hasil penelitian menunjukkan bahwa dalam satuan luas dan waktu yang sama ternyata dalam usaha tanam padi dapat memberikan banyak penyerapan tenaga kerja bila dibandingkan dengan usaha tani TRI, oleh karena itu untuk mengisi waktu luang akibat kelebihan tenaga kerja yang tidak termanfaatkan selama berlangsungnya usaha tani padi, maka kepada 
mereka diharapkan untuk dapat membantu perbaikan program TRI sebagaimana tujuan pemerintah untuk meningkatkan pendapatan petani mencapai sasaran maksimal dan positip.

b. Pengaturan periode glebagan terutama di lahan sawah basah perlu didasari pertimbangan-pertimbangan yaitu tanaman mana yang lebih banyak mendatangkan keuntungan bagi petani merupakan pilihan utama. Serta target pabrik gula (PG) apabila di wilayahnya sudah tercukupi, terutama sistem glebagan di daerah lahan sawah basah hendaknya dialihkan di lahan sawah kering.

c. Uang CLO (Cost of Living) yang diterima petani perlu memperoleh perhatian, agar petani tebu selama masa tunggu bisa menikmati hidup nya hingga memetik hasil panennya. Sehingga petani tebu apabila ekonominya baik maka tidak mudah terjerat sistem ijon (seperti menjadi permainan bola bagi petani bermodal besar).

d. Disamping itu yang paling penting adalah perlu diperbaikinya cara cara perhitungan rendemen tebu milik petani dengan cara yang lebih terbuka, penghitungan rendemen hendaknya tidak merugikan lagi pada petani dan mampu mengeliminir terjadinya berbagai penyimpangan-penyimpangan yang sering dikeluhkan para petani tebu. e. Pinjaman/pencairan kredit untuk biaya pengelolaan TRI hendaknya sistem administrasi diperlancar, agar petani langsung sudah menerima uangnya sehingga dalam mengusahakan tani tebu bisa tepat waktunya, dan

f. Perlu ditingkatkan terutama kepada pabrik gula (PG), KUD, dan ketua kelompok tani dalam hal memberi kan pelayanan/bimbingan teknis cara bercocok tanam tebu yang ba$\mathrm{ik}$, agar dapat membantu meningkat kan taraf hidup petani tebu.

Dari uraian saran-saran tersebut di atas mudah-mudahan dapat memberi kan jalan keluar kepada PG maupun para petani tebu tentang masalah yang dihadapinya, sesungguhnya bukan persoalan perlu tidaknya meski Inpres No. 9 Tahun 1975 menggariskan pelaksanaan program TRI hendaknya menjadikan petani sebagai tuan ditanahnya sendiri itu perlu ditinjau kembali. Akan tetapi disini yang lebih penting adalah bagaimana cara menempatkan dan memberi wewenang kepada para petani tebu agar supaya mereka bisa mempunyai hak otoritas yang kuat dan kebebasan.

Dengan demikian petani tebu agar tidak mudah terjebak/dijadikan sebagai obyek saja atau dijadikan alat permainan dari pihak yang lebih kuat, melainkan petani tebu hendaknya mempunyai posisi yang lebih kuat baik dari segi sosial ekonomi maupun politik dan lain sebagainya. 
Untuk itu dengan harapan seperti apa yang dimaksudkan dalam tujuan pemerintah yakni tentang program TRI bekerjasama dengan lembaga- lembaga yang terkait hendaknya bersama-sama memantau hasil yang positif.

\section{DAFTAR PUSTAKA}

Aksi Agraris Kanisius, 1992, Budi Daya Tanaman padi. Aksi Agraris. Yayasan Kanisius; Yogyakarta.

Amipro, S. 1987. Kajian Kesesuaian Lahan Melalui Foto Udara Daerah Lereng Selatan Gunung Api Merapi Antara Kaliurang Hingga Parangtritis Daerah Istimewa Yogyakarta. Tesis S2. Program Studi Penginderaan Jauh. Fakultas Pasca Sarjana UGM; Yogyakarta.

Anonim, 1997. Pedoman Bercocok Tanam Padi dan Sayur-sayuran. Badan Pengendalian Bimas Departemen Pertanian Indonesia; Jakarta.

Anonim, P.N. 1997. Himpunan Pekerjaan Dalam Kursus Tebu Rakyat Intensifikasi. P.N. Perkebunan XVI; Solo

Anonim, 1988. Teknologi Sapta Usaha Intensifikasi Tebu. Makalah Rapat Kerja Tim Teknis Sekretariat BP. Bimas dan Perusahaan Gula. tanggal 29-30 Juni; Yogyakarta.

Anonim, 1990. Varietas Tebu Unggul Lekal Untuk Tegalan dengan Pola Koperasi. Makalah Seminar Pembangunan Agro Industri Berbasis Tebu dan Sumber Pemanis lain. Departemen Pertanian; Jakarta.

Birowo, A.T. 1978. Kebijaksanaan Tri Marta Pembangunan Pertanian dan Perkebunan, Makalah Ilmiah Disajikan pada Simposium perkebunan di Universitas Gadjah Mada; Yogyakarta.

Bintarto, R. dan Surastopo Hadisumarno. 1979. Metode Analisa Geografi. LP3ES; Jakarta.

Geertz, L. 1976. Involusi Pertanian Proses Perubahan Ekologi Bulanan. P3PK; Jakarta. 
Hadiyanto, 1983. Tebu Rakyat Intensifikasi di Mata Petani Seminar Bulanan. P3PK; Yogyakarta.

Kayam, U. 1990. Laporan Sementara Penelitian Sosial Budaya Program Tebu Rakyat Intensifikasi di Jawa. Kerjasama Dewan Gula di Indonesia dengan Pusat Penelitian Kebudayaan Universitas Gadjah Mada; Yogyakarta.

Mantra, J.B. 1985. Pengantar Studi Demografi. Nurcahya; Yogyakarta

Mubyarto, 1977. The Sugar Industry: From Estate to small holdercane Production, BIES vol. XII No. 2; Yogyakarta

1984. Masalah Industri Gula di Indonesia. BPES; Yogyakarta.

1984. Kredit Pedesaan dan Peranannya dalam Penciptaan Peluang Bekerja dan Peluang Berusaha. P3PK; Yogyakarta.

1984. Masalah-masalah Industri Gula di Indonesia. BPFE; Yogyakarta.

Mubyarto, Daryanti, 1991. Gula Kajian Sosial Ekonomi. Aditya Media; Yogyakarta.

Panekoek, A.J. 1949. The Out Line of The Geomorphology of Java. Geologikal Survey. Hearlem.

Rambo, A.T. 1981. Interductory Essay: The Conceptual Developtment of Human Ecology. Henululu Hawaii.

Repelita V, 1989/1990-1993/1994. Kantor Sekretariat Negara; Jakarta.

Roehadi H.W., Soeyanto. 1988. Perlindungan Tanaman Tebu di Lahan Kering Wilayah P.T.P. XXIV-XXV (Persero). Makalah Seminar. Budidaya Tanaman Tebu Lahan Kering tanggal 23-25 Nopember; Pasuruan.

.Roell, W. 1971. Stuktur Pemilikan Tanah di Indonesia. Yayasan Obor; Jakarta.

Rogers, EM. and Shenneker, FF. 1971 Communication of Inovations: A Cross Cultural Approach. Free Press; New York.

Samsudin. 1989. Sosial Ekonomi : Dampak Sosial Program Tebu Råkyat Intensifikasi terhadap Petani Kasus Desa Sidomulyo Kecamatan Bambang Lipuro Kabupaten Bantul. Skripsi Sarjana Fakultas Geografi Universitas Gadjah Mada; Yogyakarta.

Sayogyo, 1978. Lapisan Masyarakat yang paling Lemah di Pedesaan Jawa. Prisma. UII, 3 (4); Jakarta.

Simatupang, M.S. 1989. Pemanfaatan Lahan di Desa Salam Magelang, Skripsi Sarjana Fakultas Geografi Unversitas Gadjah Mada; Jakarta.

Soentoro, 1979. Kemungkinan Program Tebu Rakyat Intensifikasi sebagai usaha Pemerataan Pendapatan. Survey Agro Ekonomi; Bogor. 
Suhardjo, A.J, 1983. Geografi Pedesaan dan Pembangunan Agro Ekonomi No. 22. Perhepi; Jakarta.

, 1983. Azas-azas Pembangunan Masyarakat. Makalah disampaikan pada penataran dan lokakarya Pengelolaan pada Pengabdian Masyarakat di Perguruan Tinggi 30 Januari 1983; Bogor.

Suparyono, Agus Setyono. 1993. Padi. Penerbit Swadaya; Jakarta.

Surachmad, W. 1970. Dasar dan Teknik Research: Pengantar Metodologi Ilmiah. Tarsito; Bandung.

Jally, R. 1977. Changing Vier on Development, Surveys For Development. Editor: J. Nessin. Elsevier Scientific Publishing Company; Amsterdam.

Whynne Charles-Hammond, 1979. Elements of Human Geography. George Allen \& UNWIN; London. 